\title{
Progress in Research on 5-HTTLPR under Stress and Thyroid Papillary Carcinoma
}

\author{
Liumei Luo' ${ }^{1}$, Juncheng Guo ${ }^{2 *}$, Fengxia Chen ${ }^{1}$, Min Guo ${ }^{1}$, Ping Huang ${ }^{3}$ \\ ${ }^{1}$ Hainan General Hospital, Haikou, China \\ ${ }^{2}$ Haikou Hospital Affiliated to Xiangya School of Medicine, Central South University, Haikou, China \\ ${ }^{3}$ University of South China, Hengyang, China \\ Email: *g2002m@163.com
}

How to cite this paper: Luo, L.M., Guo, J.C., Chen, F.X., Guo, M. and Huang, P. (2019) Progress in Research on 5-HTTLPR under Stress and Thyroid Papillary Carcinoma. Journal of Behavioral and Brain Science, 9, 325-339.

https://doi.org/10.4236/jbbs.2019.99024

Received: August 2, 2019

Accepted: September 8, 2019

Published: September 11, 2019

Copyright $\odot 2019$ by author(s) and Scientific Research Publishing Inc. This work is licensed under the Creative Commons Attribution International License (CC BY 4.0).

http://creativecommons.org/licenses/by/4.0/

\section{(c) (i) Open Access}

\begin{abstract}
The central nervous system plays an important role in regulating thyroid hormone homeostasis. 5-HT is one of the important neurotransmitters involved in energy balance regulation. 5-HT transporters affect 5-HT function by regulating SERT protein expression and transcriptional activity. Based on the biological correlation between thyroid hormone and thyroid tumors, 5-HTTLPR is associated with thyroid tumors under stress. Animal models of thyroid disease have shown that some of the transmitters in the brain's monoaminergic nervous system have changed, and when the monoamine transporter gene expression is altered, it is found that this disorder is more pronounced. This article discusses whether thyroid papillary carcinoma patients are associated with 5-HTTLPR and whether the mechanism of thyroid papillary carcinoma "gene $\mathrm{x}$ environment" has an effect. Briefly describe the role of 5-HTTLPR in the development of patients with papillary thyroid carcino$\mathrm{ma}$, and provide a basis for clinical diagnosis and treatment of papillary thyroid cancer.
\end{abstract}

\section{Keywords}

5-HTTLPR, Hyroid Papillary Carcinoma, Central Nervous System, Clinical Diagnosis, Treatment

\section{Introduction}

Normal thyroid function is essential for the development, growth and metabolic balance of the human body, the prerequisite is that the thyroid is well developed and there is no abnormality in iodine uptake and thyroid hormone synthesis [1]. Thyroid function may be impaired when there is any defect in thyroid develop- 
ment and thyroid hormone synthesis [2]. Papillary thyroid carcinoma (PTC) is the most common in endocrine system tumors, and its incidence has increased year by year in recent years, and it is increasingly harmful to human health [3]. Because most of the clinical aspects of PTC have no typical malignant biological behavior, they are sometimes difficult to distinguish from benign thyroid diseases [4]. Thyroid gland resection is the most important method for the treatment of PTC, but even with radical tumor resection, $20 \%-30 \%$ of PTC patients will have tumor recurrence or metastasis, which will increase their mortality [5]. In the past few decades, papillary thyroid carcinoma (PTC) has been one of the most common endocrine malignancies in East Asia. Papillary thyroid carcinoma, the most common thyroid cancer phenotype, accounts for $70 \%-80 \%$ of all thyroid cancers [6]. In recent years, with the progress and development of society, the pace of people's life is accelerating, and people are exposed to various stressful events in their work, study, and life, and the prevalence of psychosomatic diseases is increasing year by year [7]. It impacts and dramatically changes the disease spectrum and death spectrum of modern society with surprisingly high morbidity and high mortality [8]. The thyroid gland, the largest endocrine organ in humans, is essential in promoting the basal metabolism, growth and development of the body [9]. Recent studies have suggested that stress has an important impact on the occurrence and development of papillary thyroid carcinoma and has become one of the biggest environmental hazards in today's society. Therefore [10], it is very important to study the association between 5-HTPPRPR and the prognosis of patients with papillary thyroid carcinoma under stress.

\section{Stress Response in Patients with Papillary Thyroid Carcinoma}

With the popularization of ultrasound and the improvement of pathological biopsy at home and abroad, the incidence of PTC is also increasing year by year [11]. Although PTC is a good type of malignant tumor with a good prognosis, the 10-year survival rate can be as high as about $89 \%$ [12]. When the invasive PTC continues to develop distant metastatic lesions, the patient's survival rate will be significantly reduced. Radioactive iodine 131 is one of the main postoperative treatment modes for metastatic PTC. It is often poor in patients with distant metastasis, and the 10-year survival rate can even drop to about $10 \%$ [13]. Therefore, early diagnosis of PTC and finding excellent tumor metastasis markers have been one of the hotspots of PTC research [14]. Foreign scholars report that the prognosis of PTC is related to factors such as 5-HTTLPR under stress state in patients with papillary thyroid carcinoma [15]. Stress is a kind of mental tension caused by the "unbalance" between the body and the environment after the body is strongly stimulated. Stress events are diverse, including emotional stress such as life stress, emergencies, cancer patients, emotional causes, or flashing, loud, high temperature, freezing, electric shock, oscillation, 
infection, surgery, childbirth, etc [16]. To a certain extent, the stress response is the need of the body to actively adapt to environmental changes, it can arouse and exert the body's potential and enhance the ability to resist and resist disease. However, if the reaction is too strong or long-lasting, beyond the body's own ability to regulate and control, it may lead to disorders of psychophysiological function and cause mental disorders and physical illnesses (psychosomatic diseases) [17]. The following are a series of direct or indirect effects of stress on a person's physiology, psychology, and behavior. The physiological response of the body during physiological stress is a non-specific process, and various systems, tissues and organs will undergo different degrees of physiological and biochemical changes [18]. In the early stages of stress, mainly the excitability of the sympathetic nervous system, the release of a large amount of catecholamines from the adrenal medulla and sympathetic nerve endings, leading to increased heart rate, increased myocardial contractility, increased cardiac output, elevated blood pressure, cerebrovascular and bone Increased muscle blood flow, increased breathing, increased skeletal muscle tone, increased secretion of various hormones, promote the decomposition of protein, fat, glycogen, increase blood sugar levels, accompanied by digestive tract peristalsis and secretion reduction, sweating and so on. A series of physiological and psychological responses caused by the same stimuli have significant individual differences [19]. British research suggests that the response to stress depends not only on stimuli, but also on individual cognition, evaluation, and personality traits (temperament, personality, ability), personality orientation (needs, motivation, interest), beliefs, and social support and other factors. Stress can disrupt the body's hormone secretion and metabolism of homeostasis, causing nervous, circulatory, endocrine and other system disorders, manifested as physical diseases, especially endocrine disorders, including obesity, diabetes, hyperthyroidism and other diseases The relationship is closer [20]. Stress is an important environmental factor that affects thyroid function and induces thyroid disease [21]. Although its specific pathogenesis has not yet been fully elucidated, clinicians should be fully aware of the potential harm of stress to the development and progression of autoimmune thyroid diseases, especially Graves' disease (toxic diffuse goiter), pay attention to the psychotherapy of the patient [22]. Stress is ubiquitous in life, especially in the modern society, which makes human beings suffer more and more complex and increasingly physical and psychological stress [15]. Abnormal stress response can affect the homeostasis (internal homeostasis) of the internal environment through various stress media, causing damage to the body. Various traumas can cause stress response in the body, excessive stress can lead to thyroid and its ultra-micro Pathological changes in the structure [23].

\section{Papillary Thyroid Carcinoma and Serotonin Transporter Gene}

The incidence of mental illness in patients with papillary thyroid carcinoma is 
very high, especially in thyroid papillary carcinoma combined with depression. According to data published by the World Health Organization, the prevalence of depression worldwide is about 3\% [24], and the prevalence of depression in patients with papillary thyroid cancer is as high as 30\% [25]. A retrospective study by British scholars found that major depression may increase the incidence of thyroid disease [26]. number of studies have confirmed that emotional response stress can directly affect the function of pancreatic thyroid gland through physiological mechanisms including autonomic nervous pathways, neuroendocrine mechanisms and vagus nerves, thereby inducing thyroid disease or accelerating the progression of thyroid disease Long-term endocrine disorders in patients with papillary thyroid carcinoma, the body is under high stress, and the increase of various stress factors and intensity will in turn increase the prevalence of depression or aggravate depression [27]. In recent years, a large number of studies have shown that antidepressant intervention in patients with thyroid papillary cancer depression is significantly beneficial to patients with thyroid hormone control; at the same time, good thyroid hormone control can reduce the patient's depression. These indicate that there may be a biological relationship between papillary thyroid carcinoma and depression, but not two independent diseases, suggesting that the neuroendocrine system may play an important role in regulating thyroid hormone secretion. Depression is mainly due to dysfunction of 5-HT (hypothesis) and norepinephrine (hypothesis) [27]. Its clinical manifestations are depression, slow thinking, decreased will, and physical symptoms. 5-HT is an important neurotransmitter in the body. In recent years, studies have shown that serotonin $(5-\mathrm{HT})$ plays an important role in maintaining glucose homeostasis, and related studies have also shown that it is associated with papillary thyroid carcinoma [28]. It is associated with complications such as complications, drug dependence, and the thyroid system. Serotonin transporter (5-HTT/SERT) is the main transporter of 5-HT and plays an important role in regulating the physiological function of 5-HT [29]. The serotonin transporter gene-linked polymorphic region (5-HTTLPR) affects 5-HT function by regulating SERT protein expression and transcriptional activity [30]. Numerous studies have shown that 5-HTTLPR is strongly associated with post-traumatic stress disorder (PTSD) disease, especially depression, and even some scholars call it a "depression gene" [31]. Inspired by the above theoretical basic researchers, it is speculated that 5-HTTLPR may also affect thyroid hormone metabolism. Based on the above research theories and foundations, this study intends to explore the correlation of 5-HTTLPR gene polymorphism in patients with thyroid tumors, and provide a basis for the study of the etiology of patients with thyroid papillary carcinoma under stress, in order to study thyroid papillary Cancer neuroendocrine provides a theoretical basis for the treatment of thyroid papillary carcinoma or papillary thyroid carcinoma combined with depression [32]. Studies have shown that the central nervous system plays an important role in regulating thyroid hormone homeostasis. $5-\mathrm{HT}$ is one of the im- 
portant neurotransmitters involved in energy balance regulation. The 5-HT transporter (Serotonin transporter, SERT or 5-HTT) is the major transporter of 5 -HT, and when 5-HT is released into the synaptic cleft, it is responsible for transport and inactivation. SERT/5-HTT transporter protein expression is mainly regulated by the 5-HTT gene. The serotonin transporter gene-linked polymorphic region (5-HTTLPR) is the main regulatory region of the 5-HTT gene, which affects 5 -HT function by regulating SERT protein expression and transcriptional activity. Many studies have confirmed that 5-HTTLPR is strongly associated with papillary thyroid carcinoma. Based on the biological correlation between thyroid hormone and thyroid tumor, is it speculated that 5-HTTLPR is also associated with thyroid tumor under stress? An animal model of the initial thyroid disease showed some changes in the brain's monoaminergic nervous system. When the monoamine transporter gene expression was changed, the disorder was found to be more pronounced. Subsequent studies on humans have shown that 5-HTTLPR gene polymorphism is associated with papillary thyroid carcinoma. Several other studies have shown that the 5-HTTLPR gene polymorphism is associated with post-traumatic stress disorder. Based on the above theoretical basis, this paper intends to explore whether patients with papillary thyroid carcinoma are associated with 5-HTTLPR. Based on this, we will further describe the role of 5-HTTLPR in the development of patients with papillary thyroid carcinoma. Papillary carcinoma provides a certain basis for clinical diagnosis and treatment [33]. Although many scholars have conducted extensive and in-depth research on the mechanism of "gene $\mathrm{x}$ environment" of papillary thyroid carcinoma, and explained it to a certain extent, which laid the foundation for our research and provided some inspiration, but through our summary, there are still some shortcomings in these previous studies.

\section{Post-Traumatic Stress Disorder in Patients with Thyroid Cancer}

Thyroid cancer is considered to be the most common malignancy in the endocrine system, and its incidence has experienced a 3-fold increase in the past 30 years [34]. According to major histology, well-differentiated thyroid cancer accounts for approximately 9/10, including follicular thyroid cancer (FTC) or papillary thyroid carcinoma (PTC) [35]. In addition, papillary thyroid carcinoma appears to be a more common type, and patients over the age of 45 usually have extended soft tissue or lymph node metastasis, and are even more prone to recurrence and death [36]. Post-traumatic stress disorder is a frequently occurring disease that affects mental and/or physical health due to extreme adverse events [37]. Patients diagnosed with post-traumatic stress disorder will endlessly and uncontrollably think about unpleasant events for quite some time [38]. In addition, cancer survivors have lower confidence, but concerns about death and recurrence have increased due to post-traumatic stress disorder [39]. Therefore, in order to treat these patients more effectively, it is necessary to better understand 
the mechanism for improving the prognosis of papillary thyroid carcinoma associated with post-traumatic stress disorder. A previous study pointed out that more and more victims of well-differentiated thyroid cancer, especially for a long time, highly recommended follow-up [40]. It is said that certain genes may be responsible for the development of papillary thyroid carcinoma, such as the Forkhead box E1 (FOXE1) that has a negative impact [41]. Considering the following unpleasant cancer psychological experiences, Schillani et al. have determined that 5-HTTLPR is a contributing factor to adverse emotions in breast cancer psychiatry [42]. In addition, post-traumatic stress disorder is a common and costly disease whose primary medical burden is related to cancer and is difficult to identify and manage [43]. In recent years, the serotonin transporter gene (5-HTTLPR) has received attention for its involvement in mental disorders [44]. For example, the role of the 5-HTTLPR polymorphism in the promoter region of the solute carrier family 6 member 4 (SLC6A4) has been revealed for the prediction of PTSD [45]. In terms of the number of base pairs, the 5-HTTLPR polymorphism can usually be divided into two forms, including "short" (S) or "long" (L), which have three different combinations, including short and long (SL), short and short (SS) and long and long (LL) [46]. A meta-analysis performed by Gressier et al. showed that the SS genotype was associated with post-traumatic stress disorder in subjects exposed to severe trauma [47]. The mortality caused by PTC is low, patients must observe after surgery to prevent any recurrence, and long-term tightness may lead to psychological problems [48]. An important finding of our study was that the 5-HTTLPR SS genotype was associated with PTSD and led to poor clinical outcomes and results in patients with PTC. As discussed in functional studies, the negative effects of PTSD on cancer may lead to the impaired immune system, which further weakens the body's resistance to tumor development, and stress-related hormones may also affect tumor growth [49]. The involvement of the serotonin transporter gene has previously revealed sensitivity to psychopathology and stress [50]. Our results are consistent with the statements made by Caspi et al. Individuals carrying the LL genotype are more likely to suffer from depression than individuals carrying the SL or SS genotype [51]. Similarly, Artero et al. showed that younger individuals with SS genotypes carrying the 5-HTTLPR polymorphism were more likely to be depressed or even suicidal than patients with LL genotypes [52]. Most related studies by Karg et al. also concluded that the S allele of 5-HTTLPR is associated with a higher likelihood of depression under stress conditions [53]. A team of surgical results has mentioned that the $S$ allele of 5-HTTLPR is involved in the decreased expression of serotonin transporters and may be a dangerous allele for depression, especially in patients with SLE [54]. The transcription efficiency of the $\mathrm{S}$ allele may be lower than that of the $\mathrm{L}$ allele, and the $\mathrm{S}$ allele is related to the function and structure of the brain, thus affecting the susceptibility to gene-related PTSD [55]. Similarly, early studies have shown that the 5-HTTLPR genotype is associated with poor survival after colorectal surgery, 
and that modulation of 5-HTT activity may be the cause of inflammatory changes [56]. In conclusion, the 5-HTTLPR SS genotype led to a downward psychological problem with PTC.

\section{Treatment of Papillary Thyroid Carcinoma}

Papillary thyroid carcinoma is a common endocrine system malignant tumor. In recent years, with the change of environment, the incidence of papillary thyroid carcinoma in the world has increased, and with the development of ultrasound medicine, the early stage of papillary thyroid carcinoma The diagnosis is accurate and rises, which provides a more favorable opportunity for $f$ surgery. Currently, thyroid papillary carcinoma is still mainly treated by surgery, but there are certain differences at home and abroad. Traditional surgery is still the mainstream solution for treating such diseases. However, with the development of medical technology, new surgical methods such as ultrasound-guided percutaneous ablation are gradually being taken seriously, which also provides new ideas for the treatment of papillary thyroid carcinoma.

\subsection{Diagnosis of Papillary Thyroid Carcinoma}

The onset of thyroid micropapillary carcinoma is more insidious. It can also be called occult thyroid cancer. Most patients have no obvious symptoms in the early stage of the disease. It is difficult to diagnose the diagnosis in the early stage of hospital diagnosis. Clinical studies have shown that most patients find thyroid microtubular carcinoma because they found a thyroid nodule to the hospital. The results of the survey showed that the probability of thyroid micropapillary carcinoma combined with sputum thyroid enlargement was $2.2 \%$ to $9.3 \%$, and the majority of patients were women aged 30 - 50 years [57]. The patient underwent a high-resolution ultrasound. Help patients to diagnose and receive treatment as soon as possible. In general, the ultrasonographic examination of thyroid micropapillary carcinoma results in a low-resistance I sound, irregular shape, and unclear boundaries. It can see enhanced small spots [58]. Studies have shown that about $30 \%$ of patients with thyroid micropapillary carcinoma have signs of microcalcification, and $78.5 \%$ of patients with thyroid micropapillary carcinoma have irregular tumor margins. And the tumor anteroposterior diameter is larger than the transverse diameter of malignant tumor [49]. For patients with suspicious ultrasound findings, family history, and history of cervical radiation, local biopsy should be performed under ultrasound guidance before surgery to determine the nature of the lesion before surgery can be performed [50].

\subsection{Current Status of Surgical Treatment of Primary Papillary Thyroid Carcinoma}

At present, thyroid papillary carcinoma is mainly treated with surgery. Regarding the treatment of papillary thyroid carcinoma, especially for the treatment of 
small lesions, the American Thyroid Association (ATA) recommends that the affected side of the gland and the spleen resection be performed, but only for single lesions. Non-metastatic cases are with a lower risk. The European Society of Oncology (EsMO) has also made similar recommendations. However, the pathological type was further supplemented, and it was pointed out that the case of glandular lobectomy and isthmic resection should be follicular subtype cancer, infiltrating follicular carcinoma or typical papillary carcinoma, so most foreign countries still undergo total thyroidectomy for treatment [51]. The choice of surgical plans in China is slightly different from that in foreign countries. The indications for glandular lobe and spleen resection are: 1) limited single lesion of unilateral thyroid; 2) no history of head and neck radiation exposure in childhood, low recurrence risk of distant metastasis; 3) no contralateral nodule Section. Considering that the thyroidectomy will affect the patient's endocrine function, and it will damage the recurrent laryngeal nerve, the proportion of total thyroidectomy in China is relatively low. This may be related to the current medical situation in China [52]-[63]. The biological behavior of papillary thyroid carcinoma is relatively good. Most patients have slow growth and no obvious symptoms. There is no disease progression during the lifetime of the disease, based on which Japanese scholar proposed that some lesions do not require treatment. Good advice [64]. In Giugliano et al. [65], 322 patients with thyroid papillary carcinoma were followed up for a mean follow-up of 69 months. Patients were unable to undergo surgery because of the following problems: 1) lesion adjacent to the trachea; 2) lesion located on the dorsal side, surgery may invade the larynx Recurrent nerve; 3) puncture biopsy indicates a higher degree of malignancy; 4) may have lymph node metastasis; 5) no significant disease progression. Compared with 197 other patients with thyroid papillary carcinoma who underwent surgery, there were no significant differences in prognosis and lymphatic metastasis between the unoperated patients. Therefore, papillary thyroid carcinoma can be observed first, and some cases do not require surgery. This view is now gradually recognized in China. Some medical institutions believe that patients with papillary thyroid carcinoma $<5 \mathrm{~mm}$ in diameter are advised to observe the standard if they meet the standard [66].

\subsection{New Surgical Plan for the Treatment of Papillary Thyroid Carcinoma}

In addition to traditional surgical treatment, with the development of medical technology, the treatment of papillary thyroid carcinoma has more choices, and gradually develops in the direction of minimally invasive. According to the clinical characteristics of papillary thyroid carcinoma, under the premise of radical treatment, it is a major clinical research topic to ensure the aesthetics and minimally invasive surgery. Currently, more minimally invasive surgical procedures include complete laparoscopic surgery, Micc01i surgery, etc. The former is also known as cosmetic surgery. The probability of causing recurrent laryngeal nerve injury during operation is high, and the subcutaneous tissue damage is large. 
The lymphatic dissection effect in VII area is very limited, but the postoperative aesthetics is better: the latter is relative to open surgery. The surgical trauma is greatly reduced, but there are still minor surgical scars. With the development of ultrasound medicine, ultrasound-guided percutaneous ablation for thyroid papillary carcinoma has achieved initial results (Pacini et al. [67]). Three cases of thyroid papillary carcinoma treated by ultrasound-guided percutaneous ablation were reported. All patients were diagnosed as single thyroid papillary carcinoma by needle biopsy. No lymphatic metastasis was found. After ablation, total thyroidectomy was performed. Specimens were tested and no laser markers were found in thyroid tissue, peripheral muscles and recurrent laryngeal nerves, and the lesions were destroyed by carbonization, suggesting that laser ablation was better (Choi et al. [68]). A related report was also made. Twenty-one patients with thyroid papillary carcinoma underwent percutaneous microwave ablation. Four patients experienced varying degrees of hoarseness within 3 months after surgery. However, they all recovered within 3 months, and no recurrence was found after 1 year of follow-up. However, there are relatively few reports on ultrasound-guided percutaneous ablation for the treatment of papillary thyroid carcinoma, and the type of treatment is relatively limited, mostly for patients with a lower clinical stage, whether it can be used as a general treatment, whether TSH is needed after surgery. Further research is needed to address the issue of inhibition therapy. In addition, for papillary thyroid carcinoma, microscopic lesions are not equivalent to low-risk lesions. Although most microscopic lesions have better biological behavior, small lesions with multiple metastases in the neck can still be found. Therefore, the risk of papillary thyroid cancer should be evaluated by the biological activity of the lesion, so that the correct treatment options can be made.

\section{Outlook and Conclusion}

To investigate the relationship between 5-HTTLPR and progression of papillary thyroid carcinoma, the predictive effect of 5-HTTLPR and stressful life events on papillary thyroid carcinoma, and the role of 5-HTTLPR and thyroid tumors under stress mechanisms. The research results not only provide a new research basis for exploring the mechanism of thyroid neoplasms, but also provide a potential way for the prevention and treatment of papillary thyroid carcinoma. The expression and clinical significance of 5-HTTLPR in thyroid tumors are revealed. 5-HTTLPR and the development of thyroid tumors contribute to the prevention and treatment of papillary thyroid carcinoma, and enrich the causes and pathological data of papillary thyroid carcinoma under stress in China.

\section{Funding}

The work was supported by 2018 Hainan Provincial Key Research and Development Project (ZDYF2018133). 


\section{Conflicts of Interest}

The authors declare no conflicts of interest regarding the publication of this paper.

\section{References}

[1] Jeong, S.Y., Lee, S.-W., Kim, W.W., Jung, J.H., Lee, W.K., Ahn, B.-C. and Lee, J. (2019) Clinical Outcomes of Patients with T4 or N1b Well-Differentiated Thyroid Cancer after Different Strategies of Adjuvant Radioiodine Therapy. Scientific Reports, 9, 5570. https://doi.org/10.1038/s41598-019-42083-3

[2] Wei, L., Zhao, G., Lv, N., Wen, Q., Bai, L., Ma, Q.J. and Ji, B. (2019) Negative Remnant ${ }^{99 \mathrm{~m}}$ Tc-Pertechnetate Uptake Predicts Excellent Response to Radioactive Iodine Therapy in Low-to Intermediate-Risk Differentiated Thyroid Cancer Patients Who Have Undergone Total Thyroidectomy. Annals of Nuclear Medicine, 33, 112-118. https://doi.org/10.1007/s12149-018-1314-4

[3] Maruei-Milan, R., Heidari, Z. and Salimi, S. (2019) Role of MDM2 309T>G (rs2279744) and I/D (rs3730485) Polymorphisms and Haplotypes in Risk of Papillary Thyroid Carcinoma, Tumor Stage, Tumor Size, and Early Onset of Tumor: A Case Control Study. Journal of Cellular Physiology, 234, 12934-12940. https://doi.org/10.1002/jcp.27960

[4] Censi, S., Bodanza, V., Manso, J., Gusella, S., Watutantrige-Fernando, S., Cavedon, E., Barollo, S., Bertazza, L., Cecchin, D. and Mian, C. (2018) Amiodarone-Induced Thyrotoxicosis: Differential Diagnosis Using 99mTc-SestaMIBI and Target-to-Background Ratio (TBR). Clinical Nuclear Medicine, 43, 655-662. https://doi.org/10.1097/RLU.0000000000002207

[5] Dip, F., Falco, J., Verna, S., Prunello, M., Loccisano, M., Quadri, P., White, K. and Rosenthal, R. (2019) Randomized Controlled Trial Comparing White Light with Near-Infrared Autofluorescence for Parathyroid Gland Identification During Total Thyroidectomy. Journal of the American College of Surgeons, 228, 744-751. https://doi.org/10.1016/j.jamcollsurg.2018.12.044

[6] Romei, C. and Elisei, R. (2012) RET/PTC Translocations and Clinico-Pathological Features in Human Papillary Thyroid Carcinoma. Frontiers in Endocrinology, 3, 54.

[7] Beutel, M.E., Wiltink, J., Ghaemi Kerahrodi, J., Tibubos, A.N., Brähler, E., Schulz, A., Wild, P., Münzel, T., Lackner, K., König, J., Pfeiffer, N., Michal, M. and Henning, M. (2019) Somatic Symptom Load in Men and Women from Middle to High Age in the Gutenberg Health Study-Association with Psychosocial and Somatic Factors. Scientific Reports, 9, 4610. https://doi.org/10.1038/s41598-019-40709-0

[8] Hange, D., Mehlig, K., Lissner, L., Guo, X., Bengtsson, C., Skoog, I. and Björkelund, C. (2013) Perceived Mental Stress in Women Associated with Psychosomatic Symptoms, But Not Mortality: Observations from the Population Study of Women in Gothenburg, Sweden. International Journal of General Medicine, 6, 307-315. https://doi.org/10.2147/IJGM.S42201

[9] Liu, X.Y., Guo, Z.G., Sun, H.D., Li, W.T. and Sun, W. (2017) Comprehensive Map and Functional Annotation of Human Pituitary and Thyroid Proteome. Journal of Proteome Research, 16, 2680-2691. https://doi.org/10.1021/acs.jproteome.6b00914

[10] Germano, C.M.R., Bonato, D., Maion, V.H., da Silva de Avó, L.R., Gusmão Melo, D. and Fontanella, B.J.B. (2016) New Possible Determinants of the Quality of Life of Patients with Treated Thyroid Cancer: A Qualitative Study. Ciencia \& Saude Coletiva, 21, 2451-2462. https://doi.org/10.1590/1413-81232015218.18142015 
[11] Zhao, Y., Cao, P.L. and Zhao, H. (2019) Clinical and Pathologic Analysis of 2684 Cases of Papillary Thyroid Carcinoma in 8 Years. Journal of Clinical Otorhinolaryngology, Head, and Neck Surgery, 33, 371-375.

[12] Su, D.-H., Chang, S.-H. and Chang, T.-C. (2015) The Impact of Locoregional Recurrences and Distant Metastases on the Survival of Patients with Papillary Thyroid Carcinoma. Clinical Endocrinology, 82, 286-294. https://doi.org/10.1111/cen.12511

[13] Qiu, Z.-L., Shen, C.-T. and Luo, Q.-Y. (2015) Clinical Management and Outcomes in Patients with Hyperfunctioning Distant Metastases from Differentiated Thyroid Cancer after Total Thyroidectomy and Radioactive Iodine Therapy. Thyroid: Official Journal of the American Thyroid Association, 25, 229-237. https://doi.org/10.1089/thy.2014.0233

[14] Lu, Z.-L., Chen, Y.-J., Jing, X.-Y., Wang, N.-N., Zhang, T. and Hu, C.-J. (2018) Detection and Identification of Serum Peptides Biomarker in Papillary Thyroid Cancer. Medical Science Monitor. International Medical Journal of Experimental and Clinical Research, 24, 1581-1587. https://doi.org/10.12659/MSM.907768

[15] Stipcevic, T., Kusacic-Kuna, S., Dezeljin, M., Dodig, D., Korsic, M., Pivac, N. and Muck-Seler, D. (2009) Platelet Serotonin Concentration and Monoamine Oxidase Activity in Hypothyroid Patients. Hormone Research, 71, 207-212. https://doi.org/10.1159/000201109

[16] Foa, E.B., Huppert, J.D. and Cahill, S.P. (2006) Emotional Processing Theory: An Update. In: Rothbaum, B.O., Ed., Pathological Anxiety: Emotional Processing in Etiology and Treatment, Guilford Press, New York, 3-24.

[17] Holgersen, K.H., Klöckner, C.A., Jakob Boe, H., Weisæth, L. and Holen, A. (2011) Disaster Survivors in Their Third Decade: Trajectories of Initial Stress Responses and Long-Term Course of Mental Health. Journal of Traumatic Stress, 24, 334-341. https://doi.org/10.1002/jts.20636

[18] Johnson, P.L., Molosh, A., Fitz, S.D., Truitt, W.A. and Shekhar, A. (2012) Orexin, Stress, and Anxiety/Panic States. Progress in Brain Research, 198, 133-161. https://doi.org/10.1016/B978-0-444-59489-1.00009-4

[19] Wenner, M.M. (2018) Sympathetic Activation in Chronic Anxiety: Not Just at the "Height" of Stress. Editorial Focus on "Relative Burst Amplitude of Muscle Sympathetic Nerve Activity Is an Indicator of Altered Sympathetic Outflow in Chronic Anxiety". Journal of Neurophysiology, 120, 7-8.

https://doi.org/10.1152/jn.00220.2018

[20] Park, J., Marvar, P.J., Liao, P.Z., Kankam, M.L., Norrholm, S.D., Downey, R.M., McCullough, S.A., Le, N.-A. and Rothbaum, B.O. (2017) Baroreflex Dysfunction and Augmented Sympathetic Nerve Responses during Mental Stress in Veterans with Post-Traumatic Stress Disorder. The Journal of Physiology, 595, 4893-4908. https://doi.org/10.1113/JP274269

[21] Chinn, S.M., Monson, D.H., Tinker, M.T., Staedler, M.M. and Crocker, D.E. (2018) Lactation and Resource Limitation Affect Stress Responses, Thyroid Hormones, Immune Function, and Antioxidant Capacity of Sea Otters (Enhydra lutris). Ecology and Evolution, 8, 8433-8447. https://doi.org/10.1002/ece3.4280

[22] Juszczak, G.R. and Stankiewicz, A.M. (2018) Glucocorticoids, Genes and Brain Function. Progress in Neuro-Psychopharmacology \& Biological Psychiatry, 82, 136-168. https://doi.org/10.1016/j.pnpbp.2017.11.020

[23] Stipcevic, T, Kusacic-Kuna, S, Dezeljin, M. (2009) Latelet Serotonin Concentration and Monoamine Oxidase Activity in Hypothyroid Patients. Hormone Research, 71, 207-212. https://doi.org/10.1159/000201109 
[24] Ghimire, S., Baral, B.K., Feng, D., Sy, F.S. and Rodriguez, R. (2019) Is Selenium Intake Associated with the Presence of Depressive Symptoms among US Adults? Findings from National Health and Nutrition Examination Survey (NHANES) 2011-2014. Nutrition, 62, 169-176. https://doi.org/10.1016/j.nut.2018.12.007

[25] Tang, H.X. and Zhang, Y.S. (2018) Identification and Bioinformatics Analysis of Overlapping Differentially Expressed Genes in Depression, Papillary Thyroid Cancer and Uterine Fibroids. Experimental and Therapeutic Medicine, 15, 4810-4816. https://doi.org/10.3892/etm.2018.6023

[26] Maruyama, M., Kobayashi, S., Shingu, K., Nagashima, H., Nagamine, K., Kasuga, Y., Kato, R., Kameko, F. and Amano, J. (2000) Solitary Brain Metastasis from Papillary Thyroid Carcinoma in a Patient with Depression: Report of a Case. Surgery Today, 30, 827-830. https://doi.org/10.1007/s005950070066

[27] Karaoglu, A., Aydin, S. and Dagli, A.F. (2009) Expression of Obestatin and Ghrelin in Papillary Thyroid Carcinoma. Molecular and Cellular Biochemistry, 323, 113-118. https://doi.org/10.1007/s11010-008-9969-0

[28] Beltrami, C.A., Barbatelli, G., Criante, P., Paliaga, A. and Amadi, C.E. (1987) An Immunohistochemical Study in Thyroid Cancer. Applied Pathology, 5, 229-245.

[29] Uribe, M., Fenoglio-Preiser, C.M., Grimes, M. and Feind, C. (1985) Medullary Carcinoma of the Thyroid Gland. Clinical, Pathological, and Immunohistochemical Features with Review of the Literature. The American Journal of Surgical Pathology, 9, 577-594. https://doi.org/10.1097/00000478-198508000-00003

[30] Sato, H. and Sakai, H. (2004) Incidentaloma of the Thyroid. Nihon Rinsho. Japanese Journal of Clinical Medicine, 62, 935-939.

[31] Krisch, K., Krisch, I., Horvat, G., Neuhold, N. and Ulrich, W. (1985) The Value of Immunohistochemistry in Medullary Thyroid Carcinoma: A Systematic Study of 30 Cases. Histopathology, 9, 1077-1089. https://doi.org/10.1111/j.1365-2559.1985.tb02786.x

[32] Silberstein, E.B. (2008) Reducing the Incidence of ${ }^{131}$ I-Induced Sialadenitis: The Role of Pilocarpine. The Journal of Nuclear Medicine, 49, 546-549. https://doi.org/10.2967/jnumed.107.049411

[33] Kovacs, C.S., Masé, R.M., Kovacs, K., Nguyen, G.K. and Chik, C.L. (1994) Thyroid Medullary Carcinoma with Thyroglobulin Immunoreactivity in Sporadic Multiple Endocrine Neoplasia Type 2-B. Cancer, 74, 928-932.

https://doi.org/10.1002/1097-0142(19940801)74:3<928::AID-CNCR2820740321>3.0 .CO;2-E

[34] Costa, V., Esposito, R., Pallante, P., Ciccodicola, A. and Fusco, A. (2015) The "Next-Generation" Knowledge of Papillary Thyroid Carcinoma. Cell Cycle, 14, 2018-2021. https://doi.org/10.1080/15384101.2015.1049786

[35] Yu, X.M., Schneider, D.F., Leverson, G., Chen, H. and Sippel, R.S. (2013) Follicular Variant of Papillary Thyroid Carcinoma Is a Unique Clinical Entity: A Population-Based Study of 10,740 Cases. Thyroid, 23, 1263-1268. https://doi.org/10.1089/thy.2012.0453

[36] Henderson, Y.C., Toro-Serra, R., Chen, Y.Y., et al. (2014) Src Inhibitors in Suppression of Papillary Thyroid Carcinoma Growth. Head \& Neck, 36, 375-384. https://doi.org/10.1002/hed.23316

[37] Ravindran, L.N. and Stein, M.B. (2009) Pharmacotherapy of Post-Traumatic Stress Disorder. Current Topics in Behavioral Neurosciences, 2, 505-525.

[38] Frommberger, U., Angenendt, J. and Berger, M. (2014) Post-Traumatic Stress Disorder-A Diagnostic and Therapeutic Challenge. Deutsches Ärzteblatt Internation- 
al, 111, 59-65. https://doi.org/10.3238/arztebl.2014.0059

[39] Koutrouli, N., Anagnostopoulos, F. and Potamianos, G. (2012) Posttraumatic Stress Disorder and Posttraumatic Growth in Breast Cancer Patients: A Systematic Review. Women \& Health, 52, 503-516. https://doi.org/10.1080/03630242.2012.679337

[40] Liu, F.H., Kuo, S.F., Hsueh, C., et al. (2015) Postoperative Recurrence of Papillary Thyroid Carcinoma with Lymph Node Metastasis. Journal of Surgical Oncology, 112, 149-154. https://doi.org/10.1002/jso.23967

[41] Somuncu, E., Karatas, A., Ferahman, S., et al. (2015) The Investigation of Foxe1 Variations in Papillary Thyroid Carcinoma. International Journal of Clinical and Experimental Pathology, 8, 13458-13464.

[42] Schillani, G., Era, D., Cristante, T., et al. (2012) 5-HTTLPR Polymorphism and Anxious Preoccupation in Early Breast Cancer Patients. Radiology and Oncology, 46, 321-327. https://doi.org/10.2478/v10019-012-0024-0

[43] Hahn, E.E., Hays, R.D., Kahn, K.L., et al. (2014) Post-Traumatic Stress Symptoms in Cancer Survivors: Relationship to the Impact of Cancer Scale and Other Associated Risk Factors. Psycho-Oncology, 24, 643-652. https://doi.org/10.1002/pon.3623

[44] Suppli, N.P., Bukh, J.D., Moffitt, T.E., et al. (2015) 5-HTTLPR and Use of Antidepressants after Colorectal Cancer Including a Meta-Analysis of 5-HTTLPR and Depression after Cancer. Translational Psychiatry, 5, e631.

https://doi.org/10.1038/tp.2015.121

[45] Walsh, K., Uddin, M., Soliven, R., et al. (2014) Associations between the SS Variant of 5-HTTLPR and PTSD among Adults with Histories of Childhood Emotional Abuse: Results from Two African American Independent Samples. Journal of Affective Disorders, 161, 91-96.

[46] Sharpley, C.F., Palanisamy, S.K.A., Glyde, N.S., Dillingham, P.W. and Agnew, L.L. (2014) An Update on the Interaction between the Serotonin Transporter Promoter Variant (5-HTTLPR), Stress and Depression, Plus an Exploration of Non-Confirming Findings. Behavioural Brain Research, 273, 89-105.

https://doi.org/10.1016/j.bbr.2014.07.030

[47] Gressier, F., Calati, R., Balestri, M., et al. (2013) The 5-HTTLPR Polymorphism and Posttraumatic Stress Disorder: A Meta-Analysis. Journal of Traumatic Stress, 26, 645-653. https://doi.org/10.1002/jts.21855

[48] Gou, J., Cheng, W., Lei, J., et al. (2017) Health-Related Quality-of-Life Assessment in Surgical Patients with Papillary Thyroid Carcinoma: A Single-Center Analysis from Mainland China. Medicine, 96, e8070. https://doi.org/10.1097/MD.0000000000008070

[49] Gradus, J.L., Farkas, D.K., Svensson, E., et al. (2015) Posttraumatic Stress Disorder and Cancer Risk: A Nationwide Cohort Study. European Journal of Epidemiology, 30, 563-568. https://doi.org/10.1007/s10654-015-0032-7

[50] Navarro-Mateu, F., Escamez, T., Koenen, K.C., Alonso, J. and Sánchez-Meca, J. (2013) Meta-Analyses of the 5-HTTLPR Polymorphisms and Post-Traumatic Stress disorder. PLoS ONE, 8, e66227. https://doi.org/10.1371/journal.pone.0066227

[51] Caspi, A., Sugden, K., Moffitt, T.E., et al. (2003) Influence of Life Stress on Depression: Moderation by a Polymorphism in the 5-HTT Gene. Science, 301, 386-389. https://doi.org/10.1126/science.1083968

[52] Artero, S., Touchon, J., Dupuy, A.M., Malafosse, A. and Ritchie, K. (2011) War Exposure, 5-HTTLPR Genotype and Lifetime Risk of Depression. British Journal of Psychiatry, 199, 43-48. https://doi.org/10.1192/bjp.bp.110.087924 
[53] Karg, K., Burmeister, M., Shedden, K., Sen, S., et al. (2011) The Serotonin Transporter Promoter Variant (5-HTTLPR), Stress, and Depression Meta-Analysis Revisited: Evidence of Genetic Moderation. Archives of General Psychiatry, 68, 444-454. https://doi.org/10.1001/archgenpsychiatry.2010.189

[54] Wright, B., Alexander, D. and Aghahoseini, A. (2016) Does Preoperative Depression and/or Serotonin Transporter Gene Polymorphism Predict Outcome after Laparoscopic Cholecystectomy? BMJ Open, 6, e007969. https://doi.org/10.1136/bmjopen-2015-007969

[55] Kimbrel, N.A., Morissette, S.B., Meyer, E.C., et al. (2015) Effect of the 5-HTTLPR Polymorphism on Posttraumatic Stress Disorder, Depression, Anxiety, and Quality of Life among Iraq and Afghanistan Veterans. Anxiety, Stress, and Coping, 28, 456-466. https://doi.org/10.1080/10615806.2014.973862

[56] Savas, S., Hyde, A., Stuckless, S.N., et al. (2012) Serotonin Transporter Gene (SLC6A4) Variations Are Associated with Poor Survival in Colorectal Cancer Patients. PLoS ONE, 7, e38953. https://doi.org/10.1371/journal.pone.0038953

[57] Cho, B.Y., Choi, H.S., Park, Y.J., et al. (2013) Changes in the Clinicopanlological Characteristics and Outcomes of Thyroid Cancer in Korea over the Past Four Decades. Thyrojd, 23, 797-804. https://doi.org/10.1089/thy.2012.0329

[58] Pazaitou-Panayiotou, K., Capezzone, M. and Pacini, F. (2007) Clinical Features and Therapeutic Implicatjon of Papillary Thyroid Microcarcinoma. Thyrojd, 17, 1085-1092. https://doi.org/10.1089/thy.2007.0005

[59] Roti, E., Uberti, E.C., Bondanelli, M. and Braverman, L.E. (2012) Thymid Papillary Microcarcinoma: A Descriptive and Meta-Analysis Study. European Journal of Endocrinology, 159, 659-673. https://doi.org/10.1530/EJE-07-0896

[60] Brito, J.P., Gjonfriddo, M.R, Al Nofal, A., et al. (2014) The Accuracy of Thyroid Nodule Ultrasound to Predict Thyroid Cancer: Systematic Review and Meta-Analysis. The Journal of Clinical Endocrinology \& Metabolism, 99, 1253-1263. https://doi.org/10.1210/jc.2013-2928

[61] Trimboli, P, Guglielmi, R., Monti, S., et al. (2012) Ultrasound Sensitivity for Thyroid Malignancy Is Increased by Real-Time Elastography: A Prospective Multicenter Study. The Journal of Clinical Endocrinology \& Metabolism, 97, 4524-4530. https://doi.org/10.1210/jc.2012-2951

[62] Ifo, Y., Miyauchi, A., Inoue, H., et al. (2010) An Observational Trial for Papillary Thyroid Micmcarcinonla in Japanese Patients. World Journal of Surgery, 34, 28-35. https://doi.org/10.1007/s00268-009-0303-0

[63] Song, E., Han, M., Oh, H.-S., et al. (2019) Lobectomy Is Feasible for 1-4 cm Papillary Thyroid Carcinomas: A 10-Year Propensity Score Matched-Pair Analysis on Recurrence. Thyroid, 29, 64-70. https://doi.org/10.1089/thy.2018.0554

[64] Ito, Y., Miyauchi, A., Kihara, M., et al. (2014) Patient Age Is Significantly Related to the Progression of Papillary Microcarcinoma of the Thyroid under Observation. Thyroid, 24, 27-34. https://doi.org/10.1089/thy.2013.0367

[65] Giugliano, G., Proh, M., Gibelli, M., et al. (2014) Central Neck Dissection in Differentiated Thyroid Cancer: Technical Notes. Acta Otorrinolaringologica, 34, 9-14.

[66] Pietm, G.C., Giuseppe, P., Fabio, M., et al. (2014) Total Thyroidectomy without Prophylactic Central Neck Dissection in Clinically Node-Negative Papillary Thyroid Cancer: Is It An Adequate Treatment? World Journal of Surgical Oncology, 20, 152-160. https://doi.org/10.1186/1477-7819-12-152

[67] Pacini, F., Castagna, M.G., Brilli, L. and Pentheroudakis, G. (2012) Thyroid Cancer: ESM0 Clinical Practice Guidelines for Diagnosis, Treatment and Follow up. Annals 
of Oncology, 23, 110-119. https://doi.org/10.1093/annonc/mds230

[68] Choi, S.J., Kim, T.Y., Lee, J.C., et al. (2015) Is Routine Central Neck Dissection Necessary for the Treatment of Papillary Thyroid Microcarcinoma? Clinical and Experimental Otorhinolaryngology, 8, 41-45. 